University of Nebraska - Lincoln

DigitalCommons@University of Nebraska - Lincoln

Faculty Publications, UNL Libraries

Libraries at University of Nebraska-Lincoln

March 1972

\title{
Depth Perception as a Function of Age
}

\author{
Benjamin Bell M.D. \\ Veterans Administration Outpatient Clinic, Boston \\ Ernst Wolf Ph.D. \\ Veterans Administration Outpatient Clinic, Boston \\ Charles D. Bernholz \\ University of Nebraska-Lincoln, cbernholz2@unl.edu
}

Follow this and additional works at: https://digitalcommons.unl.edu/libraryscience

Part of the Library and Information Science Commons

Bell, Benjamin M.D.; Wolf, Ernst Ph.D.; and Bernholz, Charles D., "Depth Perception as a Function of Age" (1972). Faculty Publications, UNL Libraries. 93.

https://digitalcommons.unl.edu/libraryscience/93

This Article is brought to you for free and open access by the Libraries at University of Nebraska-Lincoln at DigitalCommons@University of Nebraska - Lincoln. It has been accepted for inclusion in Faculty Publications, UNL Libraries by an authorized administrator of DigitalCommons@University of Nebraska - Lincoln. 


\title{
DEPTH PERCEPTION AS A FUNCTION OF $\mathrm{AGE}^{1}$
}

\author{
Benjamin Bell, M.D., Ernst Wolf, Ph.D., and Charles D. Bernholz, B. A. \\ Veterans Administration Outpatient Clinic, Boston
}

\begin{abstract}
Binocular depth perception was investigated in 164 healthy Ss of the Normative Aging Study, in connection with a model of ocular aging which explains change in the dioptric media in the forties on the basis of mechanical change and later change in the retina on the basis of metabolic change. A modified Verhoeff stereopter was used. The results showed a marked diminution to make stereoptic judgments occurred in the forties decade. This is in accordance with the model. In a companion paper, retinal field shrinkage will be explored as an illustration of later metabolic age change.
\end{abstract}

The Veterans Administration has been investigating eye changes in a population of initially healthy subjects (Bell et al., 1966) on an interdisciplinary, longitudinal basis. The parameters include clinical medicine, biochemistry, anthropometry, social and psychological performance, and the special senses. In the latter category, visual function and its physiologic and morphologic correlates have been examined.

We have found that substantial physical changes of the dioptric media (lens turbidity, glare sensitivity) begin at $40-45$ years, whereas retinal (metabolic) changes begin after age 60 (Bell, 1969). The important perceptual skill of binocular depth perception was then investigated to determine its place in this model of ocular aging.

Binocular depth perception has been tested by various methods:

(1) The two-rod, or Howard-Dolman test (Howard, 1919) uses the least detectable difference in distance of two rods movable in relation to each other as a measure of stereoscopic discrimination.

(2) In the three rod test the least detectable difference between two standard rods and one moved by the examiner is determined.

(3) The Ames leaf room uses spatial distortion caused by magnification as an index of stereoscopic perception (Ogle, 1962).

(4) Ogle's space eikonometer measures differences in magnification of retinal images (Ogle, 1946).

(5) The Verhoeff stereopter uses the number of correct responses to a set of three bars at different distances (one of them closer or farther away) to measure the furthest distance at which the relative position of the three rods is seen correctly (Verhoeff, 1942).

(6) Jani (1966) has described a new device consisting of three short rods placed perpendicularly on a transilluminated diffusing screen. The testplate forming the front face of a flashlight is pointed straight toward an observer who must recognize which of the three rods is tallest. The maximum distance at which the correct answer is given represents a measure of stereopsis.

\footnotetext{
${ }^{1}$ An earlier version of this paper was presented under the title, "Stereopis and Age" at the Gerontological Society Meeting, October 1970 , Toronto, Canada.
} 
(7) The Verhoeff stereopter has been well accepted for clinical applications because of its small size and ease of operation. The measurement consists in scoring correct responses to the discriminatory task of discerning the relative position of three rods for eight possible options at a given distance.

Sloan and Gallagher (1945) compared the performance of the Howard-Dolman with the Verhoeff test. Trumbull (1951) tested the reliability of the Verhoeff test. Niven et al. (1952) have employed a modification of the standard Verhoeff test. Sloan and Altman (1954) have investigated the reliability of the Verhoeff against the Howard-Dolman test and the Armed Forces Vision Tester.

The concensus was that the Verhoeff test was a reliable and convenient tool. In the present study this instrument was used to investigate the relationship between stereoscopic perception and age by determining the number of correct responses at various distances in individuals ranging in age between 20 and 70 .

\section{METHOD}

A modified American Optical Co. Verhoeff Stereopter was used. The vertical bars were changed so that each had a width of $2 \mathrm{~mm}$., thus eliminating confusion of size-inconstancy cues. The distance in planes between the two equivalent and the odd bar remained $2.5 \mathrm{~mm}$. The $1 / 2 \times 2$ inch opening containing the bars was illuminated by a 25 watt tungsten filament lamp concealed in a housing. The stereopter was attached to a disc which could be turned $180^{\circ}$ so as to present with ease the eight bar positions incorporated in the test. The disc was behind a white screen 14 inches wide and 18 inches high in the center of which the stereopter was seen through an opening. On each side in front of the screen was a seven-watt lamp enclosed in a cylindrical housing to yield a uniform illumination of the screen's front surface. Under these conditions the only objects standing out against a uniform white background were the three bars, the relative position of which was to be determined. In order that they could be placed at various distances from the observer, the components of the apparatus were assembled on a carriage which ran on tracks mounted on a heavy wooden plank. The subject was positioned, using a head and chin rest, with his eye level to that of the window in the Verhoeff tester. The distance of the tester from the subject's eye was measured by means of a metric scale attached to the track bed (Wolf, McFarland, \& Zigler, 1960).

One hundred sixty-four healthy veterans, all participating in the Normative Aging Study carried out by the Boston Veterans Administration Outpatient Clinic, served as subjects.

During tests, a subject was correctly positioned with the aid of the head and chin rest. The trans-and front-illuminated stereopter was placed at the distance of 1 meter. To make the subject fully understand the test, he was shown a model of the three bars in different positions made out of wooden dowels which he could handle and closely examine the relative positions of the three bars. The subject was additionally told that there would always be one rod further or nearer than the other two rods and that he was to identify that rod. The three bars were presented in random order at distances of 1.00. 0.75, 0.50, and 0.25 meters.

The scores of the individuals were calculated by summing the number of correct responses at each distance and also summing the four distance scores. The maximum score would be 8 at $1,0.75,0.50$, and 0.25 meters, yielding a maximum cumulative score of 32 . Each mistake would reduce the maximum by 1 . 


\section{RESULTS}

The subjects were grouped into five age decade groups and an analysis of variance was carried out. An F-score of 69.32 with 5 and 164 df, yielded a p smaller than .001 and suggested that there was a significant difference among age groups of this series. The F-score for the between test analysis was insignificant, the difference thus being attributable to overall poorer performance by the older individuals.

T-tests between the age groups in order to discover changes in performance point to a decisive change between the group of mean age 40 years and that of mean age 50 years. Comparisons between T-test results obtained for mean age 20 as compared with mean age 30 are insignificant, compared with mean age 40 they appear slightly significant, but compared with mean ages 50,60 , and 70 they become very significant. This indicates that between mean age 40 and 50 years a critical change in stereopsis occurs.

The results are shown in Figure 1. The abscissa presents age in years, the ordinate mean percent of correct detections. The points for ages up to 40 years fall on a line of low negative slope; from age 50 upward the slope is much steeper, indicating between age 40 and 50 years a change in capability to make accurate stereoptic judgments.

\section{DISCUSSION}

The use of the modified Verhoeff test, reducing the influence of bars of unequal width, and avoiding the high contrast between the test panel and the surroundings while the stereopter is presented at predetermined positions, allows a more precise testing procedure in order to study the loss in stereoscopic discrimination with age. By bringing the stereopter closer to the observer in fixed steps until he can identify all bar positions correctly, a reliable measure for stereoscopic perception was obtained. The results (see Figure 1) indicate that there is a critical age range between 40 and 50 years at which depth perception begins to deteriorate. A change at this age coincides with changes in the power of accomodation and convergence (Hirsch \& Wick, 1960). Up to age 40, changes in depth perception are only slight, whereas at later ages it becomes poorer. It is interesting to note that the coincidence in deterioration of stereopsis with other changes includes

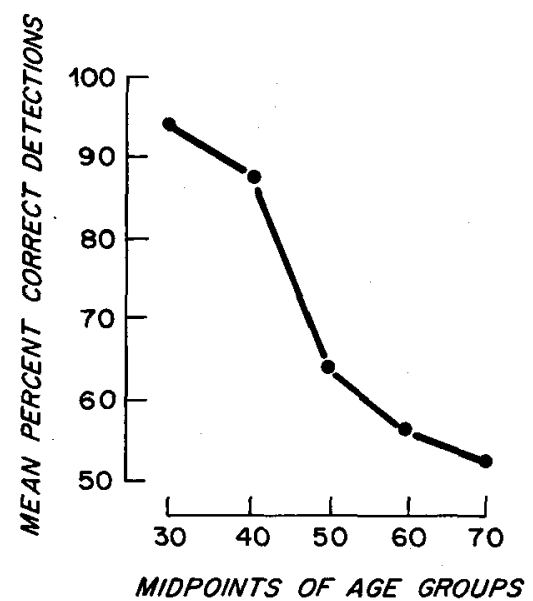

Figure 1. Mean percentages of correct discriminations of depth in different age groups (modified Verhoeff Test). 


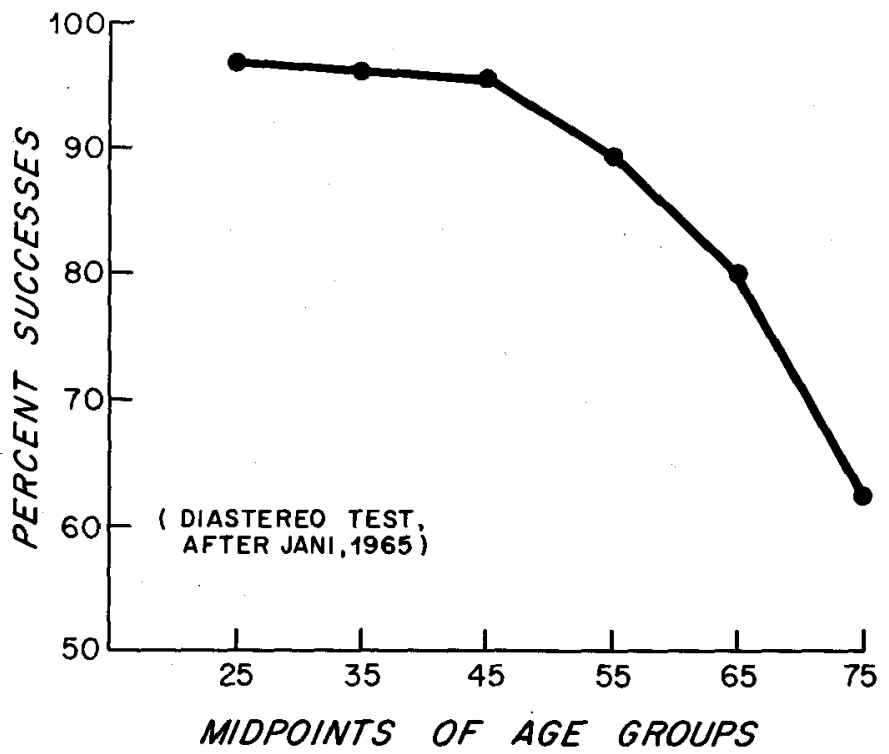

Figure 2. Mean percentages of correct identifications of depth in different age groups (Diastereo Test).

also an increase in sensitivity to glare (Wolf et al., 1960) which in turn is a function of changes in the transmissiveness of the ocular media, especially the lens (Wolf \& Gardiner, 1965).

In studies on the effects of age on vision a secondary category of changes has been observed, occuring at about age 60 years, which seems to be associated with changes in sensitivity of the retina. The level of dark adaptation exhibits a clearly noticeable alteration in individuals above 60 years (McFarland \& Fisher, 1955). Responses to flicker in individuals age 60 and over show a decline in critical flicker frequencies at all points of the visual field (Wolf \& Schraffa, 1964). The extent of the visual field as measured by dynamic perimetry decreased with age, showing an accelerated shrinkage above age 60 years (Wolf, 1967). This difference in the age of occurrence of the two categories of changes permits the assumption that the earlier changes are concerned with the mechanism of the anterior segment of the eye, and the later changes with the function of the retina and are therefore of metabolic nature.

In the study by Jani (1966) with his three prong stereo test, a change in stereopsis is clearly noticeable (Figure 2). While up to age 45 stereopsis changes only very little, it declines at a much faster rate above 45 years. This is consistent with the findings presented in this paper and supports further the assumption that the mechanical effects of aging on the anterior segment of the eye occur at an earlier age than those concerned with metabolic changes in retinal function.

It would be of utmost value to determine more clearly the nature of this mechanical-metabolic dichotomy from the longitudinal and inter-disciplinary findings of the Normative Aging Study.

\section{REFERENCES}

Bell, B. The longitudinal approach to aging studies in visual function. Proc. 8th International Congress of Gerontology, Vol. 1, 1969. 
Bell, B., Rose, C. L., and Damon, A. The Veterans Administration longitudinal study of healthy aging. The Gerontologist, 1966, 6 (4), 179-84.

Hirsch, M. G., and Wick, R. E. Vision in the aging patient. Optometric symposium. Philadelphia: Chilton Co., 1960.

Howard, H. J. A test for the judgment of distance. Amer. J. Opthal., 1919, 2, 656-675.

Jani, S. N. The age factor in stereopsis screening. Am. J. Optom. \& Arch. Am. Acad. Optom., 1966, $43,653-5$.

McFarland, R. A., and Fisher, M. B. Alterations in dark adaptation as a function of age. J. Geront., $1955,10,424-428$.

Niven, J. I., Johnson, W., Rand, G. W., and Pettit, W. A. Evaluation of a modified Verhoeff Stereopter. Project NM001 057.09.01, United States Naval School of Aviation Medicine. 1952.

Ogle, K. N. Theory of space eikonometer. J. Opt. Soc. Amer., 1946, 36, 20-32.

Ogle, K. N. Special topics in binocular spatial localization. In Davson, H., Ed., The eye, v. 4. New York: Academic Press, 1962, pp. 349-407.

Sloan, L. L., and Altman, A. Factors involved in several tests of binocular depth perception. Arch. Opthal., 1954, 52, 524-44.

Sloane, A. E., and Gallagher, J. R. Evaluation of stereopsis: a comparison of the Howard-Dolman and the Verhoeff test. Arch. Ophthal., 1945, 34, 357-59.

Trumbull, R. The reliability of the Verhoeff test of depth perception. J. Psychol., 1951, 32, 35-41.

Verhoeff, F. H. Simple quantitative test for acuity and reliability of binocular stereopsis. Arch. Opthal., 1942, 28, 1000-14.

Wolf, E., McFarland, R. A., and Zigler, M. T. Influence of tinted windshield glass on five visual functions. Highway Research Board Record, 1960, 255, 30-46.

Wolf, E. Glare and age. Arch. Opthal., 1960, 64, 502-514.

Wolf, E., and Gardiner, T. S. Studies in the scatter of light in the dioptric media of the eye as a basis of visual glare. Arch. Opthal., 1965, 74, 338-345.

Wolf, E., and Schraffa, A. M. Relationship between critical flicker frequency and age in flicker perimetry. Arch. Opthal., 1964, 72, 832-843.

Wolf, E. Studies on the shrinkage of the visual field with age. Highway Research Board Record, 1967, $167,1-7$.

This paper is from the Normative Aging Study, Benjamin Bell M.D., Director, VA Outpatient Clinic, 17 Court St., Boston, Mass. 02108. Computations were supported by funds from the Council for Tobacco Research-U.S.A. 